\title{
Variations in the Human Pain Stress Experience Mediated by Ventral and Dorsal Basal Ganglia Dopamine Activity
}

\author{
David J. Scott, ${ }^{1}$ Mary M. Heitzeg, ${ }^{1}$ Robert A. Koeppe, ${ }^{2}$ Christian S. Stohler, ${ }^{3}$ and Jon-Kar Zubieta ${ }^{1,2}$ \\ ${ }^{1}$ Department of Psychiatry and Molecular and Behavioral Neuroscience Institute and ${ }^{2}$ Department of Radiology, The University of Michigan, Ann Arbor, \\ Michigan 48109-0720, and ${ }^{3}$ School of Dentistry, University of Maryland, Baltimore, Maryland 21201
}

In addition to its involvement in motor control and in encoding reward value, increasing evidence also implicates basal ganglia dopaminergic mechanisms in responses to stress and aversive stimuli. Basal ganglia dopamine (DA) neurotransmission may then respond to environmental events depending on their saliency, orienting the subsequent responses of the organism to both positive and negative stimuli. Here we examined the involvement of DA neurotransmission in the human response to pain, a robust physical and emotional stressor across species. Positron emission tomography with the $\mathrm{DA} \mathrm{D}_{2}$ receptor antagonist radiotracer $\left[{ }^{11} \mathrm{C}\right]$ raclopride detected significant activation of DA release in dorsal and ventral regions of the basal ganglia of healthy volunteers. Activation of nigrostriatal (dorsal nucleus caudate and putamen) $\mathrm{DA}_{2}$ receptor-mediated neurotransmission was positively associated with individual variations in subjective ratings of sensory and affective qualities of the pain. In contrast, mesolimbic (nucleus accumbens) DA activation, which may impact on both $D_{2}$ and $D_{3}$ receptors, was exclusively associated with variations in the emotional responses of the individual during the pain challenge (increases in negative affect and fear ratings). These data demonstrate that basal ganglia dopamine $\mathrm{D}_{2}$ receptor-mediated neurotransmission is involved in responses to pain and that it contributes to individual variations in the pain experience at the levels of physical and emotional elements, albeit with different neuroanatomical substrates.

Key words: dopamine; saliency; reward; $\mathrm{D}_{2}$ receptors; nigrostriatal; mesolimbic

\section{Introduction}

Persistent pain represents a frequent condition and a leading cause of health and social care service. It is also a complex form of stress, with both physical and emotional elements contributing to individual variations in pain report and pain-associated disability (Stone et al., 2004; Harris et al., 2005; Sullivan et al., 2005). The understanding of neurobiological mechanisms contributing to that variability is therefore of considerable interest.

The present study examines the involvement of dopamine (DA) neurotransmission in responses to a pain stressor. At the level of mesolimbic, ventral tegmental projections to the nucleus accumbens, dopaminergic activity has been traditionally involved in the anticipation and response to natural rewards and drug reinforcers (Robinson and Berridge, 2000; Volkow et al., 2002; Nicola et al., 2005). In this context, mesolimbic DA cells are engaged in the encoding of both reward value and its uncertainty, to appropriately orient the responses of the organism (Fiorillo et al., 2003; Hsu et al., 2005; Tobler et al., 2005). However, this system also seems to respond to stressors and negative emotional states (Thierry et al., 1976; Horvitz, 2000; Pruessner et al., 2004).

Received June 19, 2006; revised Aug. 22, 2006; accepted Sept. 8, 2006.

This work was supported by the National Institutes of Health Grants R01 DA 016423 and AT 001415 (J.-K.Z.) and R01 DE 15396 (C.S.S.). We are grateful for contributions made by Positron Emission Tomography Center Nuclear Medicine Technologists (Jill M. Rothley, Edward J. McKenna, Andrew R. Weeden, Paul Kison, and Shayna Huber).

Correspondence should be addressed to Dr. Jon-Kar Zubieta, University of Michigan, Molecular and Behavioral Neuroscience Institute, 205 Zina Pitcher Place, Ann Arbor, MI 48109-0720. E-mail: zubieta@umich.edu. DOI:10.1523/JNEUROSCI.2577-06.2006

Copyright $\odot 2006$ Society for Neuroscience $\quad 0270-6474 / 06 / 2610789-07 \$ 15.00 / 0$
In the specific case of pain stimuli, it has been noted that prolonged, but not brief, pain induces the activation of nucleus accumbens DA release in rodents (Louilot et al., 1986; Schmidt et al., 2002). This may reflect the more stressful or emotionally salient characteristics of pain as it becomes temporally sustained (Stohler and Kowalski, 1999), but these processes have not been studied directly in humans.

Experiments in animal models have also suggested that DA activity in the nigrostriatal pathway is associated with pain suppression, an effect that appears mediated though $\mathrm{DA} \mathrm{D}_{2}$ receptors (Lin et al., 1981; Ben-Sreti et al., 1983; Morgan and Franklin, 1991; Altier and Stewart, 1999; Magnusson and Fisher, 2000). In this regard, the administration of levodopa, an indirect DA agonist, has been reported to reduce pain ratings in painful diabetic neuropathy in humans (Ertas et al., 1998). Contrary to these results, the systemic administration of $\mathrm{DA}_{2}$ receptor antagonists in humans has also been shown to reduce pain ratings in clinical trials (Dundee et al., 1963; Taub, 1973; Fields, 1989; Zitman et al., 1991). The existing information as to the involvement of DA mechanisms in pain is therefore conflicting from the perspective of both directionality (DA release being associated with pronociceptive or antinociceptive responses) and their localization (nigrostriatal or mesolimbic pathways).

To clarify these issues, we used positron emission tomography (PET) with $\left[{ }^{11} \mathrm{C}\right]$ raclopride, a $\mathrm{DA} \mathrm{D}_{2}$ receptor radiotracer, for the quantification of the in vivo availability of these receptors during control states and during moderate levels of sustained pain in healthy subjects. Under these conditions, reductions in regional 
receptor availability for the radiotracer reflect DA release and DA activation of $\mathrm{D}_{2}$ receptors (Laruelle et al., 1995; Endres et al., 1997) and will be referred to here as evidencing "activation" of $\mathrm{DA} \mathrm{D}_{2}$ neurotransmission. This measure of DA system activation was then related to the psychophysical pain descriptors provided by the subjects.

\section{Materials and Methods \\ Subjects}

Volunteers were 25 healthy, medication-free, right-handed men $(n=18)$ and women $(n=7) 27 \pm 5$ years of age, with an educational level of $17 \pm$ 2 years. Subjects had no personal history of medical, psychiatric illness, or substance abuse or dependence and no family history of inheritable illnesses, ascertained by physical examination, personal and family history, and review of systems. The Structured Clinical Interview for Diagnostic and Statistical Manual of Mental Disorders DSM-IV nonpatient version (First et al., 1995) was used to rule out undiagnosed psychiatric illness and substance abuse. Volunteers did not take psychotropic medications or hormone treatments, including birth control in women, for at least 6 months, were nonsmokers, and did not exercise in excess of $1 \mathrm{~h}$ three times a week or were involved in competitive exercise. Women were studied in the midfollicular phase of the menstrual cycle (days 4-12 after initiation of menses). Written informed consent was obtained in all cases. All of the procedures used were approved by the institutional Investigational Review Boards and Radioactive Drug Research Committees.

\section{Pain stress model}

Receptor quantification with PET requires a relatively prolonged period of time for the acquisition of kinetic measures and the determination of specific binding. Here pain was maintained from 45 to 65 min after the administration of radiotracer by the infusion of medication-grade $5 \%$ hypertonic saline into the relaxed masseter (jaw) muscle via a computercontrolled closed-loop system, as described previously (Zhang et al., 1993; Stohler and Kowalski, 1999). Initially, the subject-specific parameters of the system for maintaining muscle pain are established. This consists of measuring each subject response to a standard bolus injection of $0.15 \mathrm{ml}$ of hypertonic saline, infused over $15 \mathrm{~s}$. A suitable infusion rate is then estimated by comparing the individual response with the mean response of 65 individuals exposed to the same bolus. Subsequently, the adaptive controller depends on feedback from the subjects. Subjects were required to report the present pain intensity every $15 \mathrm{~s}$ on an electronic version of $100 \mathrm{~mm}$ visual analog scale (VAS), with the lower and upper bound of the scale marked with numbers 0 and 100, representing the range from "no pain" to "the most pain intensity imaginable." Based on the VAS pain intensity scores provided by the subject every $15 \mathrm{~s}$ for the reminder of the experiment, individual infusion requirements were continuously modeled and updated to keep the present pain intensity scores in the target range (40 VAS intensity units; range, 35-45) for the full duration of the experiment (Stohler and Lund, 1995; Zubieta et al., 2001). Infusion volumes, required to maintain the pre-set pain intensity, were recorded every $15 \mathrm{~s}$, and the cumulative infusion volume required over time was used as an indicator of subjects' pain sensitivity. Using this model, pain disappears 5-10 min after completion of the algesic infusion. To avoid swelling and possible tissue damage, the maximum infusion rate was limited to $250 \mu \mathrm{l} / \mathrm{min}$.

The sensory- and pain-specific affective qualities of the painful stimulus were assessed after completion of the pain challenges with the corresponding subscales of the McGill Pain Questionnaire (MPQ) (Melzack and Torgerson, 1971), as well as with 0-100 VASs of pain intensity and unpleasantness. The internal emotional state of the volunteers was rated at the same time with the Positive and Negative Affectivity Scale (PANAS) (Watson et al., 1988). These overall measures of the subjective experience of pain stress were then used for correlational analyses with the individual neurotransmitter responses and baseline binding values.

Experiment 1. An initial pilot study was undertaken to examine whether evidence of activation of DA neurotransmission on $\mathrm{D}_{2}$ receptors could be ascertained. Two PET studies with $\left[{ }^{11} \mathrm{C}\right]$ raclopride were completed in eight male volunteers. One was performed without any inter- vention (baseline), and the other included the sustained pain stress challenge. Scan order was randomized and counterbalanced between subjects. Radiotracer administrations were separated by at least $2 \mathrm{~h}$ to allow for radiotracer decay and eliminate any possible residual effects of the preceding challenge. This study provided DA $\mathrm{D}_{2}$ measurements at baseline and during pain stress using equilibrium analyses. The activation of DA $\mathrm{D}_{2}$ neurotransmission was calculated as the reduction in regional $\mathrm{DA} \mathrm{D}_{2}$ receptor availability in vivo from baseline to pain stress.

Experiment 2. In view of the possible influences of anticipatory and attentional elements of pain stress that may not be specific to nociceptive signaling, a second series of studies was conducted in a larger sample of 10 men and 7 women. In these studies, a single PET study with $\left[{ }^{11} \mathrm{C}\right] \mathrm{ra}-$ clopride was acquired over 90 min using two different challenge conditions, as described previously (Zubieta et al., 2003b). Pain stress challenges were introduced for $20 \mathrm{~min}$ starting again at $45 \mathrm{~min}$ after tracer administration, as noted above, but were preceded by a saline control challenge using isotonic $(0.9 \%)$ saline infused at the average rate required for the pain stress challenges. This condition is invariably not associated with pain (Stohler and Kowalski, 1999; Zubieta et al., 2001, 2002, 2003b). The saline control state was introduced $5 \mathrm{~min}$ after tracer administration during the same scanning session, and subjects rated pain intensity every $15 \mathrm{~s}$ in a manner identical to that of the actual pain challenges. Subjects were blind as to when the pain challenge was to take place and were instructed to expect pain during the rating periods. The saline control challenge was followed by a $15 \mathrm{~min}$ resting period. The last $10 \mathrm{~min}$ of this resting period were used to obtain estimates of baseline binding, as described previously (Carson et al., 1997; Watanabe et al., 2000), in the absence of pain expectation. Masseter muscle needles remained in location during the entire scanning period, including saline control, resting, and pain stress periods. Baseline to pain stress binding potential (BP) changes were assessed in a manner identical to experiment 1 , for replication purposes. In addition, Logan plot graphical analyses were used to estimate BP values during early (saline control) and late (pain stress) scan phases for subsequent subtraction of total and nonspecific components of pain stress.

\section{Neuroimaging methods}

Anatomical magnetic resonance imaging (MRI) scans were acquired on a 1.5 tesla scanner (Signa; General Electric, Milwaukee, WI). Acquisition sequences were axial spoiled gradient-recalled acquisition in a steady state inverse recovery prepared MR [echo time (TE), $5.5 \mathrm{~ms}$; repetition time (TR), 14; inversion time, $300 \mathrm{~ms}$; flip angle, $20^{\circ}$; number of excitations (NEX), 1; 124 contiguous images; $1.5 \mathrm{~mm}$ thickness], followed by axial T2 and proton density images (TR, $4000 \mathrm{~ms}$; TE, 20 and $100 \mathrm{~ms}$, respectively; NEX, 1; 62 contiguous images, $3 \mathrm{~mm}$ thick) to rule out intracranial pathology.

PET scans were acquired with a Siemens (Knoxville, TN) $\mathrm{HR}^{+}$scanner in three-dimensional mode [reconstructed full-width at halfmaximum (FWHM) resolution, $\sim 5.5 \mathrm{~mm}$ in-plane and $5.0 \mathrm{~mm}$ axially], with septa retracted and scatter correction. Participants were positioned in the PET scanner gantry using the orbitomeatal line aided by the scanner gantry laser lights, and two intravenous (antecubital) lines were placed. A light forehead restraint was used to eliminate intrascan head movement. $\left[{ }^{11} \mathrm{C}\right]$ raclopride was synthesized at high specific activity $(>2000 \mathrm{Ci} / \mathrm{mmol})$ by the reaction of $\mathrm{O}$-desmethyl raclopride with ${ }^{11} \mathrm{C}$ methyl triflate; $10-15 \mathrm{mCi}$ were administered in each of the two scans. Fifty percent of the $\left[{ }^{11} \mathrm{C}\right]$ raclopride dose was administered as a bolus, and the remaining $50 \%$ was administered by continuous infusion for the remainder of the study. Under these conditions, equilibrium conditions are achieved after $35 \mathrm{~min}$ after tracer administration (Carson et al., 1997). Twenty-eight frames of images were acquired over 90 with an increasing duration (30 s up to $10 \mathrm{~min}$ ). The total mass of raclopride injected was $0.089 \pm 0.047 \mu \mathrm{g} / \mathrm{kg}$ per scan, ensuring that the compound was administered in tracer quantities, i.e., subpharmacological doses.

Images were reconstructed using iterative algorithms (brain mode; Fourier rebinning with ordered subsets-expectation maximization, 4 iterations, 16 subsets; no smoothing) into a $128 \times 128$ pixel matrix in a $28.8 \mathrm{~cm}$ diameter field of view. Attenuation correction was performed through a 6 min transmission scan $\left({ }^{68} \mathrm{Ge}\right.$ source) obtained before the 
PET study, also with iterative reconstruction of the blank/transmission data, followed by segmentation of the attenuation image. Small head motions between emission scan frames were corrected by an automated computer algorithm for each subject before analysis, and the images were coregistered to each other with the same software (Minoshima et al., 1993). Time points were then decay-corrected during reconstruction of the PET data. Image data were then transformed on a voxel-by-voxel basis into two separate sets of parametric maps. In all cases (experiments 1 and 2), these included (1) a tracer transport measure ( $K_{1}$ ratio), and (2) a receptor-related measure at equilibrium (DVeq), the latter using data obtained from the 45-90 min after tracer administration. The DVeq measure was obtained using the ratio of brain activity to activity in the cerebellum (Carson et al., 1997; Watanabe et al., 2000); $f_{2} B_{\max } / K_{\mathrm{d}}$ (or DVeq -1$)$ was the "receptor related" measure $\left(D A D_{2}\right.$ receptor availability, BP; the term $f 2$ refers to the concentration of free radiotracer in the extracellular fluid and is considered to represent a constant and very small value). In the case of experiment 2 , baseline $\mathrm{BP}$ values were obtained from 35-45 min after tracer administration using identical methods. In addition, and in experiment 2 , the tracer transport and binding measures were also calculated using a Logan plot analysis (Logan et al., 1996) using the cerebellar cortex as the reference region. With the tracer administration protocol used, the Logan plot becomes linear by $4-5 \mathrm{~min}$ after the start of radiotracer administration, with its slope being the distribution volume ratio (DVR), a measure equal to $\left(f_{2} B_{\max } / K_{\mathrm{d}}\right)+1$. The Logan analyses permitted the calculation of BP during the saline control condition (pain is expected and not received, pain is rated every $15 \mathrm{~s}$ as during the actual pain challenges) and used data from 5 to $35 \mathrm{~min}$ after tracer administration. To ensure that no systematic biases would be present when comparing early and late scan periods with Logan plots, we examined the baseline studies in the eight subjects from experiment 1 . No significant differences in $\mathrm{DA} \mathrm{D}_{2}$ binding measures from 5-35 and 45-90 min were observed with Statistical Parametric Mapping SPM2 software (Wellcome Department of Cognitive Neurology, University College London, London, UK) up to a threshold of $p=0.01$ uncorrected for multiple comparisons.

Raclopride is an antagonist at the level of both $\mathrm{D}_{2}$ and $\mathrm{D}_{3}$ receptors. In the dorsal basal ganglia, this radiotracer only binds to $D_{2}$ receptors, whereas in the ventral basal ganglia, one-third of the signal may be contributed by $\mathrm{D}_{3}$ receptors (Seeman et al., 2006). Findings in dorsal regions will then be referred to as reflecting $\mathrm{DA}_{2}$ neurotransmission, and $\mathrm{DA}$ $\mathrm{D}_{2} / \mathrm{D}_{3}$ in ventral areas.

$K_{1}$ and BP images for each experimental period and magnetic resonance images were coregistered to each other and to the International Consortium for Brain Mapping (ICBM) stereotactic atlas orientation (Meyer et al., 1997). The accuracy of coregistration and nonlinear warping algorithms was confirmed for each subject individually by comparing the transformed MRI and PET images with each other and the ICBM atlas template.

\section{Image data analysis}

Differences between conditions were mapped into stereotactic space using $t$ maps of statistical significance and random effects with SPM2 and Matlab software (MathWorks, Natick, MA), with a general linear model and correction for multiple comparisons (Friston et al., 1995). No global normalization was applied to the data, and therefore the calculations presented are based on absolute $f_{2} B_{\max } / K_{\mathrm{d}}$ estimates. Only regions with specific $D A D_{2} / D_{3}$ receptor $B P$ were included in the analyses (voxels with DVR values $>1.2$ times the mean global image as calculated with SPM2). To compensate for small residual anatomic variations across subjects and to improve signal-to-noise ratios, a three-dimensional Gaussian filter (FWHM of $6 \mathrm{~mm}$ ) was applied to each scan.

Significant effects were detected using a statistical threshold that controls a type I error rate at $p=0.05$ after correction for multiple comparisons. These were estimated using the Euler characteristic (Worsley et al., 1992) based on the number of voxels in the gray matter and image smoothness and the extent of local changes (correction for cluster volume) (Friston et al., 1991). Numerical values for the changes in DA $\mathrm{D}_{2} / \mathrm{D}_{3}$ binding, as well as for the calculation of correlations and $r$ values, were extracted from the image data by averaging the values of voxels contained in an area in which significant effects were obtained in the voxel-by-voxel analyses, down to a threshold of $p=0.01$.

\section{Results}

\section{Psychophysics}

The pain maintenance system resulted in average 0-100 VAS pain intensity ratings, acquired every $15 \mathrm{~s}$ for the $20 \mathrm{~min}$ challenge, of $34 \pm 13$ units across the 25 subjects studied. The infusion volume of algesic substance (intramuscular 5\% hypertonic saline) required for the maintenance of pain at the target level, an objective measure of pain tolerance of which the subjects were not aware, averaged $1.5 \pm 0.8 \mathrm{ml}$. Ratings acquired at the completion of the pain challenge averaged $41 \pm 18$ VAS units for pain intensity and $42 \pm 22$ for pain unpleasantness. MPQ total ratings of pain were $21.9 \pm 10.1$, MPQ sensory subscale scores were $13.8 \pm 6.0$, and MPQ pain affect subscale scores were $1.8 \pm 2.6$. The PANAS, evaluating the internal negative affective state of the volunteers, obtained before and after pain stress scans, averaged $3.2 \pm 4.4$ and $5.4 \pm 5.7$, respectively (paired $t$ test; $\mathrm{df}=24 ; t=$ $2.40 ; p<0.03)$.

\section{$\mathrm{DA} \mathrm{D}_{2}$ system activation during pain stress compared with baseline}

In an initial pilot study, eight male volunteers were studied under baseline (no intervention) and sustained pain stress conditions in two separate PET studies to ascertain the feasibility of detecting enhancements in $\mathrm{DA} \mathrm{D}_{2}$ neurotransmission with pain stress (ascertained as reductions in $\mathrm{DA}_{2} \mathrm{BP}$ ). Pain challenges were introduced in the left masseter muscle.

Voxel-by-voxel $t$ tests using SPM2 and the ICBM stereotactic coordinate system demonstrated significant pain stress-induced activation of DA neurotransmission in the basal ganglia. Significant effects, after correction for multiple comparisons, were obtained in the putamen, bilaterally [left, (all coordinates are $x, y, z$, shown in mm throughout), $-26,4,9 ; z=7.73, p<0.0001$; right, $30,4,1 ; z=4.52, p<0.05$ ], the caudate nucleus, bilaterally (left, $-14,4,18 ; z=6.57, p<0.0001$; right, $16,13,13 ; z=5.28, p<$ 0.01 ), as well as in the right (contralateral to pain) nucleus accumbens (coordinates, $11,16,5 ; z=5.34, p<0.01$ ). The average percentage reductions in the in vivo $\mathrm{DA} \mathrm{D}_{2}$ receptor availability in these regions were 16 and $13 \%$ in left and right putamen, respectively, 19 and $12 \%$ in left and right caudate, respectively, and 12\% in the right nucleus accumbens. which in the latter region may reflect both $\mathrm{D}_{2}$ and $\mathrm{D}_{3}$ receptor signal. These are substantial changes comparable with or superior to those observed in response to pharmacological challenges known to induce massive release of DA into synaptic and extracellular spaces (Martinez et al., 2003; Narendran et al., 2004).

Receptor availability data were then extracted for the regions above and then compared with pain ratings and a measure of pain tolerance. The objective measure of sustained pain tolerance used (the total volume of algesic stimulus required to maintain the pain for each subject) was inversely correlated with the activation of DA $\mathrm{D}_{2}$ neurotransmission in the right caudate $(r=-0.70 ; p<$ 0.05).

Positive correlations were obtained for MPQ total $(r=0.74$; $p=0.04)$ and MPQ sensory subscale $(r=0.74 ; p=0.04)$ scores, VAS intensity $(r=0.84 ; p<0.01)$ and VAS unpleasantness $(r=$ $0.84 ; p<0.01$ ), and DA activation in the right caudate. Right caudate activation was also positively correlated with the increase in negative PANAS affect scores from baseline to pain stress conditions $(r=0.88 ; p<0.005)$, with a trend in the same direction for the right nucleus accumbens $(r=0.68 ; p=0.06)$. 


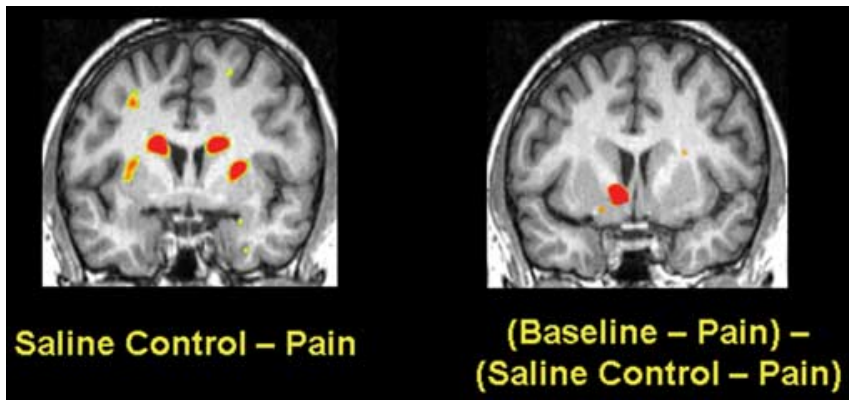

Figure 1. Localization of $D A D_{2}$ receptor activation during pain in humans. Areas of significant activation of $\mathrm{DA}_{2}$ neurotransmission during pain, superimposed over an anatomical MRI in coronal views. The left image shows the activation attributable to pain signal (pain - saline control subtraction), localized in the dorsal nucleus caudate and putamen. The magnitude of activation is correlated with sensory and pain affect ratings of the pain. The right image depicts the signal remaining from the activation of $D A D_{2}$ neurotransmission during pain after painspecific elements are subtracted: (baseline - pain) - (saline control - pain). The latter is localized in the nucleus accumbens region and associated with the internal negative affective state experienced during pain.

\section{$\mathrm{DA}_{2}$ system activation during pain stress, controlling for} pain nonspecific components

In the studies above, we could not examine the contribution of elements not specific to pain (e.g., directed attention to ratings, pain expectation, and needle placement) when comparing the data with a baseline study without intervention. In a second series, a larger sample of 17 subjects was studied under identical conditions of sustained pain stress, administered 45 min after tracer administration but using a saline control state. The latter involved the infusion of nonpainful isotonic saline and every $15 \mathrm{~s}$ ratings of pain in a manner identical to that of the actual pain challenge with expectation that pain may take place. A 15 min resting period (baseline, no pain expectation) preceded the pain stress challenge.

Changes in DA receptor availability from baseline (needle in place, no pain expectation) to pain stress states were observed in two large, bilateral clusters of the basal ganglia, incorporating both dorsal caudate and putamen and the right nucleus accumbens (left cluster, peak coordinates, $-15,14,15$; cluster size, 3174 $\mathrm{mm}^{3} ; z=9.20 ; p<0.0001$ after correction for multiple comparisons; right cluster peak coordinates, 16, 19, 6; cluster size, 4054 $\mathrm{mm}^{3} ; z=9.47 ; p<0.0001$ after correction for multiple comparisons). These findings replicated those obtained in experiment 1 but using a fixed baseline (pain order and a single scanning period).

Subtraction of saline control and pain stress data (DA responses controlling for pain nonspecific elements, such as ratings and pain expectation) showed gains in DA activity that were exclusively restricted to the dorsal caudate (bilaterally, left, $-15,4$, $20 ; z=6.6 ; p<0.0001$; right, 17, 2, 20; $z=6.9 ; p<0.0001)$ and putamen (bilaterally, left, $-26,4,8 ; z=6.1 ; p<0.0001$; right, 27, 11,$9 ; z=7.5 ; p<0.0001$ ) (Fig. 1). The average percentage reductions in $\mathrm{DA} \mathrm{D}_{2}$ receptor availability from saline control to pain stress conditions were $11 \%$ in left and right caudate and 6 and $12 \%$ in the left and right putamen, respectively. No significant DA activation was observed in the nucleus accumbens.

For the regions identified here, positive correlations were obtained between $\mathrm{DA} \mathrm{D}_{2}$ system activation in the right caudate and right putamen and MPQ total scores $(r$ values $=0.62$ and 0.63 , respectively; $p<0.01)$ and MPQ sensory $(r$ values $=0.57$ and $0.53 ; p<0.05)$, and MPQ pain affect $(r$ values $=0.66$ and 0.67 ; $p<0.005$ ) subscale scores (Fig. $2 A$ ). No significant correlations
A

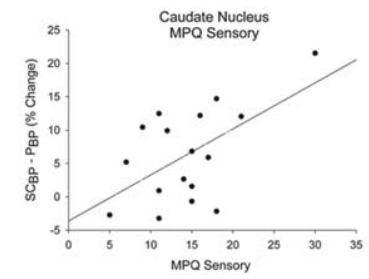

B

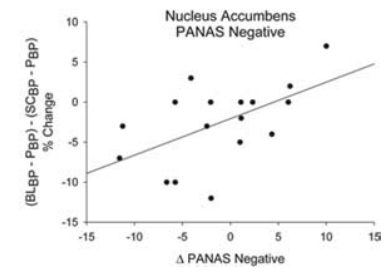

Figure 2. Correlations between activation of $D^{2} D_{2}$ neurotransmission during pain and the volunteer's subjective ratings. $\boldsymbol{A}$, Significant correlation between the pain-specific activation of dorsal caudate $D A D_{2}$ neurotransmission (percentage reductions in $D_{2}$ receptor $B P$ from saline control to pain) ( $\mathrm{SC}_{\mathrm{BP}}-\mathrm{P}_{\mathrm{BP}} \%$ Change) and $\mathrm{MPQ}$ sensory subscale scores ratings ( $r=0.57 ; p<$ $0.05)$. $B$, Significant correlation between the activation of nucleus accumbens $D A D_{2}$ neurotransmission during nonspecific elements of pain stress [(baseline - pain) - (saline control pain subtraction), shown as $\left(\mathrm{BL}_{\mathrm{BP}}-\mathrm{P}_{\mathrm{BP}}\right)-\left(\mathrm{SC}_{\mathrm{BP}}-\mathrm{P}_{\mathrm{BP}}\right)$ on the figure] and enhancements in the negative affective state of the volunteers during pain as measured by the PANAS negative affect subscale ratings ( $\Delta$ PANAS Negative) $(r=0.64 ; p<0.01)$.

between regional $\mathrm{DA}_{2}$ system activation and changes in PANAS negative affect scores were obtained.

DA $D_{2} / D_{3}$ activation in the nucleus accumbens and the subjective experience of pain stress

We then examined the relevance of nucleus accumbens DA $\mathrm{D}_{2} / \mathrm{D}_{3}$ activity to the subjective experience of pain stress, by comparing the data from baseline pain stress and saline control pain stress analyses in the larger sample of 17 subjects. The difference between those two contrasts delineated an area of DA activity localized in the right nucleus accumbens (extending into the ventral area of the caudate, contralateral to pain; coordinates, 12,16 , 0 ; cluster size, $954 \mathrm{~mm}^{3}$; $z=7.1 ; p<0.0001$ after correction for multiple comparisons) (Fig. 1) that could not be accounted for by the perception of pain itself. Activation of $\mathrm{DA} \mathrm{D}_{2} / \mathrm{D}_{3}$ neurotransmission in this region was positively correlated with painassociated increases in PANAS ratings of negative affect $(r=0.64$; $p<0.01)$ (Fig. $2 B)$ and fear $(r=0.61 ; p<0.01)$. No significant correlations were obtained between nucleus accumbens DA $\mathrm{D}_{2} / \mathrm{D}_{3}$ system activation and pain-specific ratings.

Baseline $\mathrm{DA} \mathrm{D}_{2}$ receptor availability and pain psychophysics Resting levels of $\mathrm{DA} \mathrm{D}_{2}$ receptor $\mathrm{BP}$ in the putamen have been associated with cold and heat pain thresholds in healthy volunteer samples (Hagelberg et al., 2002; Pertovaara et al., 2004; Martikainen et al., 2005). We examined whether similar relationships between baseline $\mathrm{DA} \mathrm{D}_{2}$ binding measures of pain sensitivity would be obtained in the 25 subjects scanned. VAS pain intensity ratings to the standardized $150 \mu \mathrm{l}$ of bolus of hypertonic saline that initiated the pain challenge (acute pain sensitivity) were positively correlated with right putamen $\mathrm{DA} \mathrm{D}_{2} \mathrm{BP}(r=0.44 ; p<$ $0.05)$. The total infusion of hypertonic saline required for pain maintenance, a measure of sustained pain tolerance, was negatively correlated with $\mathrm{DA} \mathrm{D}_{2} \mathrm{BP}$ in the same region $(r=-0.42$; $p<0.05)$. These data are then consistent with that published by others in both the directionality and localization on this effect.

\section{Discussion}

The present work demonstrates the involvement of DA receptormediated neurotransmission in the human responses to sustained pain stress, as measured by $\left[{ }^{11} \mathrm{C}\right]$ raclopride and PET. This radiotracer labels $\mathrm{D}_{2}$ receptors in the dorsal basal ganglia, whereas in ventral regions, approximately one-third of its bind- 
ing may reflect $\mathrm{D}_{3}$ receptor populations (Seeman et al., 2006). We ascertained the activation of DA release in dorsal (nigrostriatal) and ventral (mesolimbic) basal ganglia circuits. Furthermore, the gain in DA release was positively correlated with sensory and pain affect ratings and with the negative affect experienced by the volunteers. Nigrostriatal DA $\mathrm{D}_{2}$ system activation was associated exclusively with ratings of sensory and affective qualities of the pain, whereas mesolimbic $\mathrm{DA} \mathrm{D}_{2} / \mathrm{D}_{3}$ activity was related to the increase in negative affective state and fear ratings of the volunteers during the challenge.

Dopaminergic neurons in the mesolimbic system increase their firing and the release of DA during the receipt and anticipation of rewards (Robbins and Everitt, 1996; Waelti et al., 2001; Berridge and Robinson, 2003). This mechanism is thought to underlie the reinforcing effects of both natural rewards and drugs of abuse and to mediate incentive-motivational mechanisms in goal-directed behaviors (Wise, 2004; Schultz, 2006). However, an emerging preclinical literature indicates that mesolimbic DA is also involved in responses to aversive stimuli (Thierry et al., 1976; Louilot et al., 1986; Horvitz, 2000). This has led to the hypothesis that this neurotransmitter system is more generally involved in encoding and responding to salient stimuli, regardless of their valence. Initial neuroimaging studies in humans seem to support this view. For example, dorsal and ventral basal ganglia blood flow, as measured with functional MRI, increases during gambling tasks when there is anticipation of both monetary gain and loss (Knutson et al., 2000) and in response to the presence of nonrewarding, infrequent, and therefore more salient, distractors (Zink et al., 2003). Activation of DA $\mathrm{D}_{2} / \mathrm{D}_{3}$ neurotransmission in the ventral striatum has also been shown during a psychological stress task using molecular imaging techniques similar to those of the present work (Pruessner et al., 2004).

We observed DA release and $\mathrm{DA} \mathrm{D}_{2} / \mathrm{D}_{3}$ receptor activation in the ventral basal ganglia (nucleus accumbens and ventral portion of the caudate nucleus) in analyses when the receptor availability in the pain stress state was compared with a baseline state. Conversely, these effects were no longer significant in comparisons in which the control state incorporated the expectation of pain receipt, suggesting that anticipatory elements accounted for a substantial proportion of DA activation in this region. This is consistent with the involvement of the mesolimbic dopaminergic system in anticipatory responses, albeit typically studied in the context of predicted reward (for review, see Wise, 2004; Schultz, 2006). More relevant to the understanding of individual variations in the experience of pain stress, the gains in nucleus accumbens DA activity were positively associated with the enhancement in negative affect and fear ratings during pain stress. This finding is an important step in understanding the dissociation between physical and emotional responses to pain stress in humans and the known interindividual variations in ratings of pain and emotional state in clinical samples (Giesecke et al., 2003; Harris et al., 2005).

These data contrast with that of some animal models, whereby the inactivation of the nucleus accumbens core by the administration of an analgesic agent has been associated with hyperalgesic responses to Formalin (Magnusson and Martin, 2002). In the rodent, evidence of DA release in the nucleus accumbens has been shown for prolonged, but not brief, pain challenges (Louilot et al., 1986; Schmidt et al., 2002), an effect that was associated with reductions in pain behavior. However, these reductions in pain behavior were blocked by an opioid receptor antagonist, suggesting their mediation by the activation of downstream endogenous opioid systems (Gear et al., 1999; Schmidt et al., 2002).
This interpretation is supported by microdialysis studies in rodents demonstrating the release of endogenous opioid peptides in the nucleus accumbens by drugs activating DA neurotransmission (Olive et al., 2001).

The second circuit implicated in pain-induced DA release, the nigrostriatal pathway, has been typically involved in motor functions, particularly the initiation of motor responses. However, dorsal areas of the striatum also receive projections from somatosensory cortex (Haber et al., 2000). Initial reports have described increases in acute thermal pain sensitivity after the destruction of substantia nigra neuronal bodies and reductions during its stimulation and enhancement in striatal DA release (Lin et al., 1981). DA-depleting neurotoxins have also been shown to reduce morphine- and amphetamine-induced analgesia in the Formalin rodent model. Increases in pain thresholds have also been described after $\mathrm{DA} \mathrm{D}_{2}$ receptor agonist administration, systemically or directly in the dorsal striatum (Altier and Stewart, 1999; Magnusson and Fisher, 2000). However, the opposite effects have also been shown in some animal models (e.g., visceral pain, deafferentization pain), in which the systemic and intracerebroventricular administration of $\mathrm{DA} \mathrm{D}_{2}$ antagonists was associated with antinociceptive effects (Lyerly et al., 1988; Frussa-Filho et al., 1996; Weizman et al., 2003). These results were also similar to those of human clinical trials with $\mathrm{DA}_{2}$ receptor antagonists (Fields, 1989; Zitman et al., 1991). Finally, higher pain thresholds have been described in $\mathrm{DA}_{2}$ receptor knock-out mice for some pain models (Mansikka et al., 2005), as well as enhancements of morphine-induced analgesia (King et al., 2001). The existing literature is therefore conflicting and further confounded by the known interactions between DA and opioid circuits (Chen et al., 1993; Unterwald, 2001; Zubieta et al., 2003a).

The present work demonstrates gains in DA neurotransmission in dorsal (nigrostriatal) basal ganglia terminal fields during a painful state in humans. As was observed with the ventral, mesolimbic regions, increases in DA activity in these areas were associated with a more pronounced subjective experience. However, in the case of the dorsal caudate and putamen, DA activation was exclusively correlated the individual ratings of the sensory and unpleasant qualities of the pain, as defined by the McGill Pain Questionnaire word descriptors, and not with the emotional state of the volunteers during the challenge.

Last, we replicate findings by another group describing negative relationships between basal $\mathrm{DA}_{2}$ receptor availability in the putamen and phasic and tonic pain thresholds in healthy volunteers (Hagelberg et al., 2002; Pertovaara et al., 2004; Martikainen et al., 2005). Consistent with these data, we observed a positive correlation between putamen $\mathrm{DA}_{2}$ receptor $\mathrm{BP}$ measures and ratings of pain intensity to a standard, acute pain stimulus and negatively with a measure of sustained pain tolerance in the pain model used. That same group has reported reductions in presynaptic dopamine turnover, as measured with $\left[{ }^{11} \mathrm{C}\right]$ fluorodopa and PET, in patients diagnosed with idiopathic mouth-burning syndrome (Jääskeläinen et al., 2001). However, these findings were not replicated in a study of atypical facial pain patients (Hagelberg et al., 2003).

This report is the first demonstration of $\mathrm{DA}_{2}$ system activation in response to pain stress in humans, involving both dorsal and ventral basal ganglia regions, albeit with different psychophysical implications. Dorsal caudate and putamen DA activity were associated with the subjective description of pain severity. Examination of individual variations in DA function in persistent pain conditions, which are both frequent and oftentimes disabling and difficult to treat, appears justified in view of the 
present findings. These data also indicate that DA mechanisms may be critical to explain the increasingly recognized individual differences in pain report in clinical samples (Harris et al., 2005) and, by extension, their analgesic requirements. At a more immediately practical level, it also points to the possible utility of pharmaceuticals interacting with these receptors in the treatment of pain. These are broadly available agents that may open new avenues of treatment for persistent painful conditions.

The gain in DA release in mesolimbic, nucleus accumbens terminal fields, conversely, was not specific to the physical experience of pain stress. Variations in nucleus accumbens DA activity in humans corresponded to more prominent negative emotional states during the experience of pain stress. Negative emotional states, in turn, have been associated with both more distress and poorer clinical outcomes in clinical samples, including comorbidity with other disorders (Sullivan et al., 2005; Compton and Volkow, 2006). In this regard, the baseline concentration of $\mathrm{DA} \mathrm{D}_{2} / \mathrm{D}_{3}$ receptors and gains in DA activity in the nucleus accumbens have been associated with the reinforcing effects of drugs of abuse (Volkow et al., 2004). Ventral basal ganglia DA is also thought to mediate the effects of stress to increase the likelihood of initiation and recurrence of drugs abuse (Robinson and Berridge, 2003). Variations in risk for drug abuse after initial exposures could then be mediated by individual differences in the response of this neurotransmitter system to pain, itself a physical and emotional stressor. Substantial comorbidity also exists between clinical pain syndromes and mood disorders, the neurobiology of which has been very poorly explored. Here we show that ventral basal ganglia $\mathrm{DA} \mathrm{D}_{2} / \mathrm{D}_{3}$ system function may represent an important point of interaction between the neurobiologies of emotion, reward, and pain regulation.

\section{References}

Altier N, Stewart J (1999) The role of dopamine in the nucleus accumbens in analgesia. Life Sci 65:2269-2287.

Ben-Sreti MM, Gonzalez JP, Sewell RD (1983) Differential effects of SKF 38393 and LY 141865 on nociception and morphine analgesia. Life Sci 33:665-668.

Berridge KC, Robinson TE (2003) Parsing reward. Trends Neurosci 26:507-513.

Carson RE, Breier A, de Bartolomeis A, Saunders RC, Su TP, Schmall B, Der MG, Pickar D, Eckelman WC (1997) Quantification of amphetamineinduced changes in $\left[{ }^{11} \mathrm{C}\right]$ raclopride binding with continuous infusion. J Cereb Blood Flow Metab 17:437-447.

Chen JF, Aloyo VJ, Weiss B (1993) Continuous treatment with the D2 dopamine receptor agonist quinpirole decreases D2 dopamine receptors, D2 dopamine receptor messenger RNA and proenkephalin messenger RNA, and increases mu opioid receptors in mouse striatum. Neuroscience 54:669-680.

Compton WM, Volkow ND (2006) Major increases in opioid analgesic abuse in the United States: concerns and strategies. Drug Alcohol Depend 81:103-107.

Dundee JW, Love WJ, Moore JC (1963) Alterations in response to somatic pain associated with anesthesia. XV. Further studies with phenothiazine derivatives and similar drugs. Brit J Anaesth 35:597-609.

Endres CJ, Kolachana BS, Saunders RC, Su T, Weinberger D, Breier A, Eckelman WC, Carson RE (1997) Kinetic modeling of $\left[{ }^{11} \mathrm{C}\right]$ raclopride: combined PET-microdialysis studies. J Cereb Blood Flow Metab 17:932-942.

Ertas M, Sagduyu A, Arac N, Ertekin C (1998) Use of levodopa to relieve pain from painful symmetrical diabetic neuropathy. Pain 75:275-279.

Fields HL (1989) Pain. Singapore: McGraw-Hill.

Fiorillo CD, Tobler PN, Schultz W (2003) Discrete coding of reward probability and uncertainty by dopamine neurons. Science 299:1898-1902.

First MB, Spitzer RL, Gibbon M, Williams JBW (1995) Structured clinical interview for DSM-IV axis I disorders. New York: New York Psychiatric Institute.

Friston K, Holmes A, Worsley K, Pline J, Frith C, Frackowiak R (1995) Sta- tistical parametric maps in functional imaging: a general linear approach. Hum Brain Mapp 2:189-210.

Friston KJ, Frith CD, Liddle PF, Frackowiak RSJ (1991) Comparing functional (PET) images: the assessment of significant change. J Cereb Blood Flow Metab 11:690-699.

Frussa-Filho R, Rocha JB, Conceicao IM, Mello CF, Pereira ME (1996) Effects of dopaminergic agents on visceral pain measured by the mouse writhing test. Arch Int Pharmacodyn Ther 331:74-93.

Gear R, Aley K, Levine J (1999) Pain-induced analgesia mediated by mesolimbic reward circuits. J Neurosci 19:7175-7181.

Giesecke T, Williams DA, Harris RE, Cupps TR, Tian X, Tian TX, Gracely RH, Clauw DJ (2003) Subgrouping of fibromyalgia patients on the basis of pressure-pain thresholds and psychological factors. Arthritis Rheum 48:2916-2922.

Haber SN, Fudge JL, McFarland NR (2000) Striatonigrostriatal pathways in primates form an ascending spiral from the shell to the dorsolateral striatum. J Neurosci 20:2369-2382.

Hagelberg N, Martikainen IK, Mansikka H, Hinkka S, Nagren K, Hietala J, Scheinin H, Pertovaara A (2002) Dopamine D2 receptor binding in the human brain is associated with the response to painful stimulation and pain modulatory capacity. Pain 99:273-279.

Hagelberg N, Forssell H, Aalto S, Rinne JO, Scheinin H, Taiminen T, Nagren K, Eskola O, Jaaskelainen SK (2003) Altered dopamine D2 receptor binding in atypical facial pain. Pain 106:43-48.

Harris RE, Williams DA, McLean SA, Sen A, Hufford M, Gendreau RM, Gracely RH, Clauw DJ (2005) Characterization and consequences of pain variability in individuals with fibromyalgia. Arthritis Rheum 52:3670-3674.

Horvitz J (2000) Mesolimbic and nigrostriatal dopamine responses to salient non-rewarding stimuli. Neuroscience 96:651-656.

Hsu M, Bhatt M, Adolphs R, Tranel D, Camerer CF (2005) Neural systems responding to degrees of uncertainty in human decision-making. Science 310:1680-1683.

Jääskeläinen SK, Rinne JO, Forsell H, Tenovuo O, Kaasinen V, Sonninen P, Bergman J (2001) Role of the dopaminergic system in chronic pain - a fluorodopa PET study. Pain 90:257-260.

King MA, Bradshaw S, Chang AH, Pintar JE, Pasternak GW (2001) Potentiation of opioid analgesia in dopamine2 receptor knock-out mice: evidence for a tonically active anti-opioid system. J Neurosci 21:7788-7792.

Knutson B, Westdorp A, Kaiser E, Hommer D (2000) FMRI visualization of brain activity during a monetary incentive delay task. NeuroImage 12:20-27.

Laruelle M, Abi-Dargham A, van Dyck C, Rosenblatt W, Zea-Ponce Y, Zoghbi S, Bladwin R, Charney D, Hoffer P, Kung H, Innis R (1995) SPECT imaging of striatal dopamine release after amphetamine challenge. J Nucl Med 36:1182-1190.

Lin MT, Wu JJ, Chandra A, Tsay BL (1981) Activation of striatal dopamine receptors induces pain inhibition in rats. J Neural Transm 51:213-222.

Logan J, Fowler JS, Volkow ND, Wang GJ, Ding YS, Alexoff DL (1996) Distribution volume ratios without blood sampling from graphical analysis of PET data. J Cereb Blood Flow Metab 16:834-840.

Louilot A, Le Moal M, Simon H (1986) Differential reactivity of dopaminergic neurons in the nucleus accumbens in response to different behavioral situations. An in vivo voltammetric study in free moving rats. Brain Res 397:395- 400

Lyerly MA, Rossitch Jr E, Ovelmen-Levitt J, Nashold Jr BS (1988) The deafferentation syndrome in the rat: effects of intraventricular apomorphine. Exp Neurol 100:188-202.

Magnusson JE, Fisher K (2000) The involvement of dopamine in nociception: the role of $\mathrm{D}(1)$ and $\mathrm{D}(2)$ receptors in the dorsolateral striatum. Brain Res 855:260-266.

Magnusson JE, Martin RV (2002) Additional evidence for the involvement of the basal ganglia in formalin-induced nociception: the role of the nucleus accumbens. Brain Res 942:128-132.

Mansikka H, Erbs E, Borrelli E, Pertovaara A (2005) Influence of the dopamine $\mathrm{D} 2$ receptor knockout on pain-related behavior in the mouse. Brain Res 1052:82-87.

Martikainen IK, Hagelberg N, Mansikka H, Hietala J, Nagren K, Scheinin H, Pertovaara A (2005) Association of striatal dopamine D2/D3 receptor binding potential with pain but not tactile sensitivity or placebo analgesia. Neurosci Lett 376:149-153.

Martinez D, Slifstein M, Broft A, Mawlawi O, Hwang DR, Huang Y, Cooper 
T, Kegeles L, Zarahn E, Abi-Dargham A, Haber SN, Laruelle M (2003) Imaging human mesolimbic dopamine transmission with positron emission tomography. II. Amphetamine-induced dopamine release in the functional subdivisions of the striatum. J Cereb Blood Flow Metab 23:285-300.

Melzack R, Torgerson W (1971) On the language of pain. Anesthesiology 34:50-59.

Meyer CR, Boes JL, Kim B, Bland PH, Zasadny KR, Kison PV, Koral K, Frey KA, Wahl RL (1997) Demonstration of accuracy and clinical versatility of mutual information for automatic multimodality image fusion using affine and thin-plate spline warped geometric deformations. Med Image Anal 1:195-206.

Minoshima S, Koeppe RA, Mintun MA, Berger KL, Taylor SF, Frey KA, Kuhl DE (1993) Automated detection of the intercommissural line for stereotactic localization of functional brain images. J Nucl Med 34:322-329.

Morgan MJ, Franklin KB (1991) Dopamine receptor subtypes and formalin test analgesia. Pharmacol Biochem Behav 40:317-322.

Narendran R, Hwang DR, Slifstein M, Talbot PS, Erritzoe D, Huang Y, Cooper TB, Martinez D, Kegeles LS, Abi-Dargham A, Laruelle M (2004) In vivo vulnerability to competition by endogenous dopamine: comparison of the D2 receptor agonist radiotracer $(-)-N-\left[{ }^{11} \mathrm{C}\right]$ propyl-norapomorphine $\left(\left[{ }^{11} \mathrm{C}\right] \mathrm{NPA}\right)$ with the $\mathrm{D} 2$ receptor antagonist radiotracer $\left[{ }^{11} \mathrm{C}\right]$-raclopride. Synapse 52:188-208.

Nicola SM, Taha SA, Kim SW, Fields HL (2005) Nucleus accumbens dopamine release is necessary and sufficient to promote the behavioral response to reward-predictive cues. Neuroscience 135:1025-1033.

Olive MF, Koenig HN, Nannini MA, Hodge CW (2001) Stimulation of endorphin neurotransmission in the nucleus accumbens by ethanol, cocaine, and amphetamine. J Neurosci 21:RC184(1-5).

Pertovaara A, Martikainen IK, Hagelberg N, Mansikka H, Nagren K, Hietala J, Scheinin H (2004) Striatal dopamine D2/D3 receptor availability correlates with individual response characteristics to pain. Eur J Neurosci 20:1587-1592.

Pruessner JC, Champagne F, Meaney MJ, Dagher A (2004) Dopamine release in response to a psychological stress in humans and its relationship to early life maternal care: a positron emission tomography study using $\left[{ }^{11} \mathrm{C}\right]$ raclopride. J Neurosci 24:2825-2831.

Robbins TW, Everitt BJ (1996) Neurobehavioural mechanisms of reward and motivation. Curr Opin Neurobiol 6:228-236.

Robinson TE, Berridge KC (2000) The psychology and neurobiology of addiction: an incentive-sensitization view. Addiction 95:S91-S117.

Robinson TE, Berridge KC (2003) Addiction. Annu Rev Psychol 54:25-53.

Schmidt BL, Tambeli CH, Barletta J, Luo L, Green P, Levine JD, Gear RW (2002) Altered nucleus accumbens circuitry mediates pain-induced antinociception in morphine-tolerant rats. J Neurosci 22:6773-6780.

Schultz W (2006) Behavioral theories and the neurophysiology of reward. Annu Rev Psychol 57:87-115.

Seeman P, Wilson A, Gmeiner P, Kapur S (2006) Dopamine D2 and D3 receptors in human putamen, caudate nucleus and globus pallidus. Synapse 60:205-211.

Stohler C, Kowalski C (1999) Spatial and temporal summation of sensory and affective dimensions of deep somatic pain. Pain 79:165-173.

Stohler C, Lund J (1995) Psychophysical and orofacial motor response to muscle pain: validation and utility of an experimental model. In: Brain and oral functions. Oral motor function and dysfunction (Morimoto T, Matsuya T, Takada K, eds), pp 227-237. Amsterdam: Elsevier Science.

Stone AA, Broderick JE, Shiffman SS, Schwartz JE (2004) Understanding recall of weekly pain from a momentary assessment perspective: absolute agreement, between- and within-person consistency, and judged change in weekly pain. Pain 107:61-69.

Sullivan MJ, Lynch ME, Clark AJ (2005) Dimensions of catastrophic thinking associated with pain experience and disability in patients with neuropathic pain conditions. Pain 113:310-315.

Taub A (1973) Relief of postherpetic neuralgia with psychotropic drugs. J Neurosurg 39:235-239.

Thierry AM, Tassin JP, Blanc G, Glowinski J (1976) Selective activation of mesocortical DA system by stress. Nature 263:242-244.

Tobler PN, Fiorillo CD, Schultz W (2005) Adaptive coding of reward value by dopamine neurons. Science 307:1642-1645.

Unterwald EM (2001) Regulation of opioid receptors by cocaine. Ann NY Acad Sci 937:74-92.

Volkow ND, Fowler JS, Wang GJ, Goldstein RZ (2002) Role of dopamine, the frontal cortex and memory circuits in drug addiction: insight from imaging studies. Neurobiol Learn Mem 78:610-624.

Volkow ND, Fowler JS, Wang GJ, Swanson JM (2004) Dopamine in drug abuse and addiction: results from imaging studies and treatment implications. Mol Psychiatry 9:557-569.

Waelti P, Dickinson A, Schultz W (2001) Dopamine responses comply with basic assumptions of formal learning theory. Nature 412:43-48.

Watanabe H, Endres CJ, Breier A, Schmall B, Eckelman WC, Carson RE (2000) Measurement of dopamine release with continuous infusion of [11C]raclopride: optimization and signal-to-noise considerations. J Nucl Med 41:522-530.

Watson D, Clark LA, Tellegen A (1988) Development and validation of brief measures of positive and negative affect: the PANAS scales. J Pers Soc Psychol 54:1063-1070.

Weizman T, Pick CG, Backer MM, Rigai T, Bloch M, Schreiber S (2003) The antinociceptive effect of amisulpride in mice is mediated through opioid mechanisms. Eur J Pharmacol 478:155-159.

Wise RA (2004) Dopamine, learning and motivation. Nat Rev Neurosci 5:483-494.

Worsley K, Evans A, Marrett S, Neelin P (1992) A three-dimensional statistical analysis for CBF activation studies in human brain. J Cereb Blood Flow Metab 12:900-918.

Zhang X, Ashton-Miller JA, Stohler CS (1993) A closed-loop system for maintaining constant experimental muscle pain in man. IEEE Trans Biomed Eng 40:344-352.

Zink CF, Pagnoni G, Martin ME, Dhamala M, Berns GS (2003) Human striatal response to salient nonrewarding stimuli. J Neurosci 23:8092-8097.

Zitman FG, Linssen AC, Edelbroek PM, Van Kempen GM (1991) Does addition of low-dose flupentixol enhance the analgetic effects of low-dose amitriptyline in somatoform pain disorder? Pain 47:25-30.

Zubieta JK, Smith YR, Bueller JA, Xu Y, Kilbourn M, Meyer C, Koeppe R, Stohler C (2001) Regional mu opioid receptor regulation of sensory and affective dimensions of pain. Science 293:311-315.

Zubieta JK, Smith YR, Bueller JA, Xu Y, Woike T, Kilbourn M, Meyer C, Koeppe R, Stohler C (2002) $\mu$-Opioid receptor mediated antinociception differs in men and women. J Neurosci 22:5100-5107.

Zubieta JK, Heitzeg MM, Smith YR, Bueller JA, Xu K, Xu Y, Koeppe RA, Stohler CS, Goldman D (2003a) COMT val158met genotype affects muopioid neurotransmitter responses to a pain stressor. Science 299:1240-1243.

Zubieta JK, Ketter TA, Bueller JA, Xu Y, Kilbourn MR, Young EA, Koeppe RA (2003b) Regulation of human affective responses by anterior cingulate and limbic mu-opioid neurotransmission. Arch Gen Psychiatry 60:11451153 . 